\title{
Assessing Lexical Variations: The Case of Afan Oromo and Literature's Department Research Course at the 3 Public Universities ${ }^{i}$
}

\author{
Sileshi Berhanu \\ College of Social Sciences and Humanities, Arsi University, Ethiopia
}

Received January 2, 2020; Revised January 26, 2020; Accepted February 2, 2020

Copyright $\odot 2020$ by authors, all rights reserved. Authors agree that this article remains permanently open access under the terms of the Creative Commons Attribution License 4.0 International License

\begin{abstract}
The main objective of this study was to assess lexical variations in the context of Afan Oromo and Literature Department's Research Methods course offered at the three public universities (Adama Science and Technology-ASTU, Addis Ababa-AAU and Ambo-AU) in Ethiopia. In these universities, particular course offering instructors were among the participants on the one hand. The research related books locally published ones, the relevant course outlines, including the modules prepared as supportive materials and students' thesis's at the three public universities, "Wiirtuu"-magazines for Afan Oromo Standardization Volumes 1-11 (1995-2014) were considered were used as secondary data sources, on the other hand. Instruments applied to gather data were the relevant document scrutiny, interviews and focus group discussions. After the as sessment made, significant lexical variations were portrayed as the research findings. The course offering instructors and their respective students in the study sites were also lacked consistent use of these technical terms. And some of these varied terms create misunderstandings to the readers. Thus, it was suggested by the researcher that the instructors' team work spirit within and among the universities need to be enhanced in action so that standardized terms could be produced and accessed in coherence to respective users. And a responsible and working organ would also be in place to facilitate the creation of standard research methods course related technical terms.
\end{abstract}

Keywords Lexical Variations, Afan Oromo, Research Methods

\section{Background and Rationales}

Among the many factors contributing to language change and development, general situations related to linguistic society in context could be among the major one. The expansion in mass communication in the eighteenth and nineteenth centuries, for instance, encouraged the development of printing. In addition, industrialization processes in many arenas-social, political, economic, manufacturing, and legal issues played pivotal roles in the development of languages. Enhancements of the scientific findings and diverse academic studies also boosted language development parallel to the progress. Thus, new words have been designed to exp ress new ideas and events ${ }^{1}$ including pertinent innovations.

Now embracing and learning different languages have been considered as vital for further knowledge and economic developments. The COUNCIL OF THE EUROPEAN UNION's resolution, in this connection for instance, states that “... linguistic diversity within Europe constitutes an added value for the development of economic and cultural relations between the European Union and the rest of the world; ... multilingualism contributes to developing creativity by allowing access to other ways of thinking, interpreting the world and expressing the imagination.",

Intellectualizations of languages also contribute to language development. In this regard Garvin states the following:

Language intellectualization is an important dimension of language development (cf. Ferguson, 1968; Garvin, 1973). It is a dynamic process, characteristic of most languages which are developing an expanded range of functions in their societies. In these developing languages intellectualization is a way of providing 'more accurate and detailed means of expression,

1 Andrean, Linda (ny:32) 2COUNCIL OF THE EUROPEAN UNION (21 November 2008:4-5) 
especially in the domains of modern life, that is to say in the spheres of science and technology, of government and politics, of higher education, of contemporary culture, etc.' (Garvin, 1973:43). ${ }^{3}$

The above passage, related to the South African languages, reveals that the process of language intellectualization promotes the use of language in an accurate and detail manner at higher education. In this regard: "A lthough language intellectualization may occur naturally, there is a growing consensus among language planning scholars that, in developing languages such as those of Africa, there is a need for a conscious and deliberate effort to accelerate the process and to make it more effective." 4 Here, the intended facilitation of language use and its development has been favored. However, "The main cited problem is the lack of appropriate terminology that will enable these languages to be used in modern do mains of language use such as science and technology." Thus, "Term creation for the purpose of modernizing the indigenous languages ... falls under a process called intellectualization. This is a process of accelerating the growth and development of languages. ${ }^{, 6}$ These efforts have been backed officially by the constitution of the South African Government.

In the above passages, some situations regarding how the European and the South African languages practiced development processes have been reflected in brief. And here in the Ethiopian context, very brief information about the processes and status of the Afan Oromo development has been reflected.

The pioneering and succeeding writers in Afan Oromo employing varied local scripts and/or the abroad ones were opposed by the former regimes of the country until 1991. The current script won official recognition since 1991. Onesimos Nasib's most significant contribution was the complete translation of The Holy Bible known as "वoळb. 中৯中N" - HOLY BIBLE which was printed in 1899 at St. Chrischona in Switzerland." (Mekuria, 1995:40). The then regimes did not allow the official uses of Afan Oromo in both the local and foreign scripts, Ge'ez and Lat in respectively, including the new A fan Oromo script created by Shek Bakri Saphalo in 1956. But the subsequent Military Derg regime (as of 1974-1991), allowed the use of Afan Oromo in the national radio programs and printing news (known as 'BARIISAA') and, together with 14 other Ethiopian languages, for non-formal basic education purposes, employing Amharic (Ge'ez) scripts.

After the Derg regime has been changed in 1991 and numerous functional opportunities have been flourished to

3 Rosalie Finlayson \& Mbulungeni Madiba (2002) The Intellectualisation of the Indigenous Languages of South Africa: Challenges and Prospects, Current Issues in Language Planning, 3:1, 40-61, DOI: $10.1080 / 14664200208668036$

4 Ibid.

5 Ibid.

6 Ibid. the uses of Afan Oromo. Using Afan Oromo as a medium of instruction, opportunities have been created to attend formal education at primary schools (Grades 1-8) and including the TTIs' (Teachers Training Institutes) and TTCs'(Teachers Train ing Colleges). Also Afan Oro mo as a subject continued to be offered at secondary schools both in the first and second cycles (Grades 9-10 and 11-12 respectively). A particular Afan Oromo and Literature and/or Folklore Departments at some Ethiopian public universities have been established and employed Afan Oromo as a medium of Instruction for first and Second degrees, (BA and MA). The current Constitution of Ethiopia, Article 39, No. 2 also states that "Every nation, nationality and people in Ethiopia has the right to speak, to write and to develop its language; to express and to promote its culture; and to preserve its history.", Based on this legal situation, the above and some related endeavors regarding the development of Afan Oromo functions have been made as sated below.

Attempts have been made to address lack of standardized terms in Afan Oromo by Oromia Education Bureau (OEB) and Oromia Culture and Touris m Bureau (OCTB). In this regard, a committee, comprising language experts from these Oromia Regional State's bureaus and Addis Ababa University in 1995. And the committee's activities manifested through a biannual journal called Wiirtuu. This journal has a title known as Afan Oromo Standardization Research Journal (as 'BARRUULEE QORMAATA WAALTINA AFAAN OROMOO' in Afan Oro mo). Prof. Wolff (2012) also produced a lecture on title "The Status, Prospects and Problems of Afan Oromo in Present-Day Ethiopia" at ASTU. "There is no reason, why bi- or trilingual communication, for instance, involving English, Amharic, and Afan Oromo, should not work in all subjects taught at university level." in context has been among his experimental and observational research results reflected.

\section{Statement of the Problem}

It is self-evident that currently Afan Oromo has been playing an important role as a communication tool in the social, economic and politics spheres of the country Ethiopia at large and in Oromia Regional State in particular. Among these the following could be mentioned: administration, education and training institutions including some public and a few private universities in Ethiopia. In this regard, the Oro mia Regional State bureaus, education and training institutions conduct research activities, workshops and conference including related reports considering Afan Oromo as medium.

Among the revealed relevant centers and Institutions at public universities, the Oromo Research Center (ORC),

7 The Constitution of the Federal Democratic Republic of Ethiopia. (21st August, 995). Addis Ababa: (n. p.). 
formerly established at Adama University, the current Adama Science and Technology University, the ORC moved to now has been functioning at Arsi Univerity on the one hand, and Institute of Oromo Study established at Jima University with its extended tasks there could be cited as official organs aspired in enhancing the quality cultural and academic and research tasks in Afan Oromo and in English as well.

The Oromia Regional State's Bureau of Culture and Touris $\mathrm{m}$ has also been produced so far the standardized terms nu mbered about 3506. The number of the research related lexis published in the journals (Volumes 1-11 through 1995-2014) were limited since over $89 \%$ terms' content have been related to mixed fields of studies, i.e. not focusing on a specific field of study. Research related lexis have been only about $11 \%$ as per the researcher's count (Sileshi 2013:82; Silashii-PhD, 2014:194-195; Wiirtuu 2006:215-225) from these documents.

Albeit many encouraging works in the research related course have been underway, the researcher has been observing many lexical variations in context while offering the research methods course at one of the public universities he had been working. Thus, in this study only three public universities: Adama Science and Technology (ASTU), Addis Ababa University (AAU) and Ambo University (AU) were focused by the researcher. The English terms have been served as the source knowledge for the assessment in this study.

\section{Objectives}

This study has the following two specific objectives: a) to describe some major Afan Oromo related lexical variations in the research methods' course offering context; b) to attempt to designate some reasons why these variations occurred and c) to propose some basic standardized research related lexis.

\section{Methods}

The study sites have been three public Universities: Adama Science and Technology (ASTU), Addis Ababa University(AAU) and Ambo university(AU). Purposive and available sampling was considered for the study sites and informants and/or the intended participants of the data sources selections respectively. The above two public universities were considered for these are nearest and, easily accessed to the researcher working at ASTU. And these three universities have comprised Afan Oromo Department in which research methods course has been offered. Added to this, the Oromia Culture and Tourism Bureau printed standardized journals (1-11 volumes in total, published from 1995) and the three universities' respective related Materials (Modules, Course outlines and Thes is) and other published related materials the researcher found in the local bookshops were used as the secondary data sources. Relevant documents' scrutiny, Interviews and Focus Group Discussion (FGD) were mainly used as tools for data gathering while qualitative methods has been mainly employed for this study.

\section{Results and Discussions}

The collected data, using the above stated respective sources, have been assessed. Among the obtained research related terminologies, some major research methods related, at large, and a research report writing related Lexes, in particular have first been set in English language in two appendixes (Cf. Appendix A and Appendix B). Appendix A comprises 16 lexes and Appendix B contains 9 lexes, 25 lexes in total. And the data acquired from the three public universities, the Oromia Culture and Touris m Bureau's Wiirtuu in the volumes 1-11 published journals \& the dictionary and other relevant sources of terminologies have been considered, organized and arranged as an initial system so that the variations could be depicted easily. In the similar approach, Appendixes $\mathrm{C}$ has been arranged to portray the intended proposal as one of optional standardized lexes to the research methods course (Cf. Appendix C).

And the following brief results and discussions have also been produced in line with the aforementioned objectives of this study.

\subsection{Some Lexes Variations in the Research Methods Course including Their Sources}

As per the data obtained through the document scrutiny, the following data show the variations right from the name "Research". In this regard the lexis in the English term "Research" has got at least about six terms in practice in Afan Oromo and has been provided including their respective sources.

1. QO'ANNOO, as per Mr. Ashenafi and Mr. Mesfin $(2012: 1, \ldots)$; the research methods course Module prepared at Adama Science and Technology University (ASTU);

2. QORANNOO, Mr. Leggese Geleta (2008:857); Mr. Addunyaa Barkeessaa(2011: on the book's cover and PP. I, II, ...); Mr. Dastaa Dass aalany(2013:VI, ...) and Ambo University (AU); And as per the dictionary in three languages Afan Oromo, A mharic and English) by OCTB, means "Evaluation" and "Discussion" (205:507), Ambo University (Cf. Appendix A).

3. QU'ANNOO/QORANNAA/QORMAATA, as per the Addis Ababa University (AAU), The MA thesis produced by: Mr. Lammeessaa (2007), Mr. Shamsaddiin Yusuuf (1999E.C.), Mr. Kadiir(2007) respectively; and as per the dictionary by OCTB (205:511) and Wiirtuu (1993:194), Vol. 6, also states as "Study"; 
4. QO'ANNAA, as per the Addis Ababa University-the MA thesis by Mr. Fiqaaduu (2007),

5. QORMAATA, at Adama Science and Technology University, Wiirtuu Vol. 6 (1993:194); dictionary by OCTB (205:508); (205:507)

6. QORANNAA, as per the dictionary by OCTB (205:511) and by OCTB (205:507), it means "Study";

As can be read from the above 1-6 listed lexes in Afan Oromo, one could easily perceive the variations. For instance, in the lexes QO'ANNOO, QU'ANNOO and QO'ANNAA, the major variations have been on their respective vowels types used. These varied short vowels are "O" and " $U$ " as used in the beginning of the lexes-"QO- ..." and "QU- ...," and also long vowels "...-OO" and "...-AA" as used in the last phonemes of the le xes "-NNOO" and "-NNAA." These variations have been created simply by respective writers' usage/dialects/idiolect of the language causing no major meaning differences.

Lexes on the third listed above in one University but employed three varied terminologies: QU'ANNOO, QORANNAA and QORMAATA. It was at Addis Ababa University (AAU) that the three students used in their respective research reports. The three reporters were accomplished their work the same year at the same university as indicated above.

The researcher, on the other hand, provided the term "Abstract" with its respective lexes variations in Afan Oromo including their respective sources.

1. Axareera $\left(3^{\text {rd }}\right.$ International Oromo Studies Conference 2018:31,48,54,62,64,65, )

2. Axareeraa $\left(3^{\text {rd }}\right.$ International Oromo Studies Conference 2018:34,35,44,47,51,58)

3. Axereera (Kedir 2007:ii, Fikadu 2007; $3^{\text {rd }}$ International Oromo Studies Conference 2018:33,36,39);

4. Axereeraa ( $3^{\text {rd }}$ International Oromo Studies Conference 2018:25,27,40,56)

5. Axeerara (The first Wiirtuu, Afan Oromo Research Journal 1995:85; Wiirtuu, Vol. 6; 1993 E.C./2001:176; Vol. 9, 2001:222; Vol. 10. 2005:209;)

6. Axeerera ( $3^{\text {rd }}$ International Oromo Studies Conference 2018:66)

7. Axeereraa (Lemessa 2007:iii; Desta 2013:60; $3^{\text {rd }}$ International Oromo Studies Conference 2018:43)

\section{Ariirrata (Wiirtuu, Vol. 10, 2005:1)}

The above listed varied lexes obtained from different written documents. The fifth and the eighth (Axeerara and Ariirrata) were from the same Government Bureau's-the Oromia Culture and Touris m Bureau. While the second and the third (Axereera and Axeereraa) were obtained from Addis Ababa University's MA thesis the same year-2007 and one person who privately published a research course/work related book in 2013 (Mr. Desta) accessed in some local bookshops

These differences have been occurred by employing different vowels and different words as could be observed above. These variations appeared simply by the writers' use of their dialect on the one hand and by the writers' use of the standardized lexis as formerly published in Wiirtuu by OCTB. As observed above, the same bureau, after establishing the standardized term could apply varied lexis to the article prepared in the same journal. The researcher also observed that in a research conference this same lexis has been presented in big variations. Among the collected lexes variations appeared about $90 \%$ of the m have been in the $3^{\text {rd }}$ International Oromo Studies Conference Book of Abstracts (2018:25-66). The situation in such institute entails technology assisted use of standardized lexis for future publications.

One more lexis, in the English language known as "background of the study" has been presented with about twelve variations in the eight components variations stated below.

1. Ka'insa, Bu'uura ka'umsa, Duubee, Seenduubee, Seen-duubee (Adama Science and Technology University-ASTU)

2. Ka'iinsa (Dictionary in Oromo/Galmee jechoota Afaan Oromoo by OCTB, 2005:388)

3. Seen duubee/Seenduubee (Ambo University-AU)

4. Seenduubee/duubbee/Duubee qormataa (Addis Ababa University)

5. Seenduuba (Desta 2013:59)

6. Duubbee (Fiqaaduu 2007);

7. Ka'umsa qor annichaa (Kad iir 2007:ii; Lammees saa 2007:iii)

8. Ariirrata/Seen-duuba (Addunyaa 2011:III, 52, ...)

The above listed varied lexes have been obtained mainly from the different written documents and through interviews and focus group discussions' participants at ASTU and AAU relevant instructors, MA thesis reports and research work reference book locally published in Afan Oromo. The total variations obtained above are 12 (Ka'insa, Ka'iinsa, Bu'uura, Ka'umsa, Duubee, Duubbee, Seenduubee, Seenduuba, Seen duubee, Seen-duubee, Seen-duuba and Ariirrata).

The first varied lexes (Ka'insa, Bu'uura ka'umsa, Duubee, Seenduubee, Seen-duubee) were in use at the same one university-Adama Science and Technology University. About seven varied lexes (Seenduubee/duubbee/Duubee qormataa/Ka'umsa qor annichaa /Ariirrata/ Seenduuba/Seen-duuba) were observed at one same university-AAU.

It was observed that during the different groups discussions in which 30 persons participated at the three identified Universities; only 3 instructors used the term "Ka'insa".

On the other hand, the English terms "Background" and "Statement of the problem" were used in Afan Oromo as a lexis known "Ka'umsa". But such term could create a 
communication barrier in that the original concepts convey different meanings unless specified in details with context. Furthermore, for the English language research related tern such as "Appendix" still variations in Afan Oromo have been observed. Such variations include: Maxxantuu, Dabalee, Miiltoo .... The OCTB had been published as standard term as "Miiltoo" for it in Wiirtuu 1995:91; Wiirtuu Vol. 10, 2005 :225. But, what the researcher personally encountered or experienced in this regard was that individual instructor forces his respective students to use his own term, Dabalee, disregarding the standardized term in their respective research report.

\subsection{Some Reasons for the Emerging Lexes Variations}

Based on the partic ipants'/instructors' opinions reflected in the interviews and focus group discussions, the following points were identified as causes contributing to the current lexical variations. The results were summarized under ten major points:

1. The publications of research journals (Wiirtuu), published with standardized Afan Oromo terms was not found in the Universities.

2. Very limited number of publication of the pertinent Wiirtuu was available in the book shops.

3. There was no advancement and/or improved and republications of the Wiirtuu pertinent to the research methods' lexes.

4. Presence of some rejections of the standardized terms produced and published by the OCTB-Wiirtuu. These rejections were ascribed with the academic staffs' the universities that the producers of the standardized terms were not qualified enough.

5. Concerned university staff did not have access to participate on relevant workshops, seminars and any other team works organized for standardization committee by OCTB.

6. The instructors of the research methods course have been used different terms to refer to those identified lexes based on their own personal knowledges or linguistic backgrounds.

7. Among the three public universities under this study, Ambo University had established a working team to produce standardized lexes for use in various courses offered within the department. Instructors in the remaining two universities did not practice the same nor had no other better way observed to minimize these lexes variations. Thus, lack of established academic staffs' working team for standardized lexes production at the remaining two public universities were considered among the factors to the creations and sustaining of lexes variations.

8. As has been observed in the aforementioned results and discussions, the OCTB itself did not either consistently apply the standardized lexes ones established nor explain reasons for the inconsistent uses of these lexes. For instance, for the English term: Wiirtuu, (The first Wiirtuu, Afan Oromo Research Journal 1995:85; Wiirtuu, Vol. 6; 1993 E.C./2001:176; Vol. 9, 2001:222; Vol. 10. 2005:209;) and Wiirtuu, Vol. 10 (2005:1) emp loyed "Axeerara" and "Ariirrata" respectively used in such vivid variation of lexis.

9. Individual producers and publishers of research methods related book also did not consider the former standardized le xes and simply use their local dialects in their respective works, thus, encourage lexes variations.

10. Absence of Oromo language academy with qualified human and required resources that could lead the task and develop an increasing standardized lexes were among the contributing factors to sustain the variations.

\subsection{Some Basic Standardized Research Methods Related Lexes Proposed Optionally}

As part of the results of this study, the researcher has provided a research methods lexes proposal on the Appendixes $\mathbf{C}$ and $\mathbf{D}$ of this study optionally. The researcher sees and has been considered mainly the OCTB's publications of the standardized terminologies. Over $80 \%$ of the proposed alternative lexes (Cf. Appendix $\mathrm{C}$ and Appendix D) have been from the published documents of the OCTB. The main reason for his consideration is that he knows about the members of the respective committee in action. Thus, the committee members were educated in their respective fields also relevant to the production of these terminologies. They are also equipped in the indigenous knowledge of the Oromo people. Their respective experiences have also need to be valued too, as to the researchers' knowledge and perspective.

Added to this the researcher considered economical lexes as one of the important factors as well. In this regard, a lexis containing less number of phonemes had been selected than those more phonemes containing lexes since conveying the same meaning in context. For instance, among the Afan Oromo alternative lexes for the English term "Background," we have: "Seen duubee," or "Seen duubbee" or "Seen-duubee." Here the researcher preferred the lexis known as "Ka' insa" standardized by the OCTB in that it requires less space and lesser time to use that hold the same meaning in any way.

Thus, the detailed proposed alternative standardized lexes pertinent to the research methods have been provided 
on the Appendix $\mathrm{C}$ of this study.

\section{Conclusions and Recommendations}

The lexical variations found mainly in written documents on the one hand and the data obtained from the interviews and the focus group discussions on the other hand were collected and assessed. In this regard, the English language terminologies, including respective concepts, in context were used as the major guide and sources of knowledge.

Accordingly, significant lexes variations were detected among and within the public universities at large. More lexes variations observed in ASTU and AAU than in A mbo University in particular.. The main reason for fewer lexes of variations found at Ambo University was that the respective Afan Oromo department academic staff me mbers established a working teamto create standardized terms in their respective fields of studies. And agreed up lexes had been used consistently and practices observed at Ambo University portray minimized lexical variations Also, the course outlines, module prepared and the candidate thes is work all revealed standardized use of lexes in the research methods course at AU at large.

Therefore, the following recommendations of the researcher are thought in some way to enhance the use and establishment and development of standardized lexes for the research methods course:

1. Respective Department of Afan Oromo and Literature/Folklore at the three public Universities need to share experiences, identify their respective gaps and work together to address the problems.

2. Respective organizations such as the Institutes of Oromo Studies (IOS), the Oromo Research Center and Oromia Culture and Touris m Bureau including the Oromia Education Bureau and others need to come together with their respective resources to understand the problems and plan to act and to produce better standardized lexes optionally.

3. All public Universities located in Oromia Regional State and pertinent higher education institutes need to work to understand pertinent problems and call international research conferences and sustain facilitating production and a more developed use of standardized lexes.

\section{Acknowledgements}

Above all I would like to praise the Almighty GOD who sustains my life and enabled me to develop and produce this article. I also would like to thank the two revie wers and two of my many pertinent professional colleagues Haile mariam Kekeba (PhD) and Mekonin Gemechu (PhD) who helped me to take this form.

Then, I would like to express my heartfelt gratitude to the academic staff at the three public universities for their active participation in the study in terms of providing data sources and secondary data document and the Oromo Research Center for the financial support in the course of the study.

Mr Dejene Geleta also deserves many thanks for his cooperation in the data gathering tas ks mainly from A mbo University and subsequent report and comments forwarded to the researcher. Last but not least, my wife Mrs. Lelise Awas for her committed all rounded supports provided throughout the work. 
Appendix A: Some Research Course Related English Lexes with Some Revealed Variations in Afan Oromo Lexes

\begin{tabular}{|c|c|c|c|c|}
\hline \multirow{2}{*}{$\begin{array}{l}\text { Some Research Related } \\
\text { Lexis in English }\end{array}$} & \multicolumn{3}{|c|}{ The 3 Universities } & \multirow{2}{*}{$\begin{array}{l}\text { Standardization Committee for Afan } \\
\text { Oromo-OC TB's -W IIRTUUs and its Dictionary, } \\
\text { and ... we re main sources }\end{array}$} \\
\hline & Adama Science and Te chnology & Addis Ababa & Ambo & \\
\hline Research & QO'ANNOO, QORMAATA, ... & $\begin{array}{l}\text { QORANNOO } \\
\text { /QU'ANNOO } \\
\end{array}$ & QORANNOO & $\begin{array}{l}\text { QORMAAT A, QORANNOO (Wiirtuu Vol. 61993:194; } \\
\text { Galmee Jechootaa/dictionary by OCT B }(205: 507,508)\end{array}$ \\
\hline Table of Contents & Baafata & Qabeentaa & Baafata & $\begin{array}{l}\text { Baafat a/Qabeent aa 1995:84; Jildii-2, 1989:122; Jidii 11, } \\
\text { 2006:iv/Qabiyyee Jildii 9, 2001:224-5 }\end{array}$ \\
\hline Acknowledgements & Galata & Galata & Galata & Galata \\
\hline Abstracts & Axeereraa/Axeerara & Axeerara/Axereera/Axeereraa/ & Axeerara & Axeerara $(1995: 85)$ \\
\hline $\begin{array}{ll}\text { CHAPTER } & \text { ONE: } \\
\text { INTRODUCTION } & \\
\end{array}$ & BOQONNAA TOKKO: SEENSA & BOQONNAA TOKKO: SEENSA & $\begin{array}{ll}\text { BOQONNAA } & \text { TOKKO: } \\
\text { SEENSA } & \\
\end{array}$ & Seensa $(1995: 82)$ \\
\hline 1.1 Background & Ka'insa/seen-duubee & Seenduubee/duubbee & Seen duubee/Seenduubee & Ka'iinsa (Galmee 2005:388) \\
\hline 1.2 Statement of the problem & Ka'umsa qo'annoo & Hima rakkoo qo'annichaa & Ka'umsa qorannichaa & Ka'umsa (Galmee 2005:383) \\
\hline 1.3 Objective & Kaаyуoo & Kaаyyoo & Kaаyуоo & Kaayyoo (Galmee 2005:386) \\
\hline 1.4 Significance of the study & Barbaachisummaa/Faayidaa & Barbaachisummaa/Faayidaa & Barbaachisummaa & Faayidaa (Jildii 2, 1989:123) \\
\hline 1.5 Scope of the study & Daangaa & Daangaa & Daangaa & Daangaa (Galmee 2005:149) \\
\hline $\begin{array}{l}\text { 1.6 Organization of the } \\
\text { study }\end{array}$ & Ijaarama & Qindaa'ina & Qindoomina & Ijaaramaa (Galmee jechootaa 2005:348) \\
\hline $\begin{array}{l}\text { CHAPTER TWO: } \\
\text { LITERATURE REVIEW }\end{array}$ & $\begin{array}{l}\text { BOQONNAA LAMA: } \\
\text { SAKATT A'A BARRUU }\end{array}$ & $\begin{array}{l}\text { BOQONNAA LAMA: SAKATTA'A } \\
\text { BARRUU/OGBARRUU }\end{array}$ & $\begin{array}{l}\text { BOQONNAA LAMA: } \\
\text { SAKATTA'A BARRUU }\end{array}$ & \\
\hline $\begin{array}{ll}\text { CHAPTER } & \text { THREE: } \\
\text { METHODS } & \\
\end{array}$ & MALLEN & MALAWWAM & $\begin{array}{l}\text { MALLEEN } \\
\text { QORANNICHAA }\end{array}$ & TOOFTAA (Jildii 11,2006:221) \\
\hline 3.1 Data source & Madda raga & Madda raga & Madda raga & Madda (Wiirtu 6, 1993:190; \\
\hline 3.2 Sample & Iddattoo & Iddat too & Iddattoo & Iddat too (Jildii. 10, 2005:220) \\
\hline 3.3 Tools & Maashaalee & Maashaalee & Maashaalee & ? Argachuu hindandeenye? \\
\hline 3.4 Data analysis & Mala qaaccessuu & Mala seeccaatii & Mala qaaccessuu & Xiinxaluu (Wiirtu V. 11, 2006:222) \\
\hline
\end{tabular}


Appendix B: Some Research Course Related English Lexes with some revealed Variations in Afan Oromo Lexes (Continued)

\begin{tabular}{|c|c|c|c|c|}
\hline \multirow[b]{2}{*}{ Some Research Related Lexis in English } & \multicolumn{3}{|l|}{ The 3 Uni versities } & \multirow{2}{*}{$\begin{array}{l}\text { Standardization Committee for Afan Oromo } \\
\text { OC TB's -W IIRTUUsand and its Dictionary, and ... } \\
\text { were main sources }\end{array}$} \\
\hline & $\begin{array}{ll}\text { Adama Science and } \\
\text { Technology }\end{array}$ & Addis Ababa & Amboo & \\
\hline $\begin{array}{l}\text { CHAPTER FOUR: DATA PRESENTA TON, } \\
\text { ANALYSIS AND INTERPRETATION }\end{array}$ & $\begin{array}{l}\text { DHIYEESSA, } \\
\text { QAACCESSAAFI } \\
\text { RAGAALEE }\end{array}$ & $\begin{array}{l}\text { DHIYEESSA, } \\
\text { QAACCESSAAFI HIIKA } \\
\text { RAGAALEE } \\
\end{array}$ & $\begin{array}{l}\text { DHIYEESSA, } \\
\text { QAACCESSAAFI HIIKA } \\
\text { RAGAALEE } \\
\end{array}$ & $\begin{array}{l}\text { Dhiyeessuu, ibsaafi ... ragaa } \\
\text { (Galmee Jechoota AO.... 2005:520, 622; ICT TERMS } \\
\text { IN Oromo 2005:98) }\end{array}$ \\
\hline 4.1 Data presentation & Dhiyeessa ragaalee & Xiinxala ragaalee & Dhiyeessa ragaalee & Ragaa dhiyeessuu (Galmee jechootaa 2005:520,622) \\
\hline 4.2 Data analysis \& interpretation & Qaaccessaafi Hiika Ragaalee? & & Qaaccessaafi Hiika Ragaalee? & $\begin{array}{l}\text { Balballoommii/ibsa ragaa (Würtuu Jildii } 2 \text { 1989:119) } \\
\text { Xiinxalu, Jildii 11,2006:222 }\end{array}$ \\
\hline CHAPTER FIVE: CONCLUSION & XUMURA & GUDUNFAA & GUDUNFA & XUMURA 1995:82 \\
\hline 5.1 Summary & Cuunfaa & Cuunfaa & Cuunfaa & Gumeessa/goolaba, (Wiirtuu 1995:84) \\
\hline 5.2 Finding & Argannoo & Argannoo & Argannoo & Argannoo (Galmee jechootaa 2005:41) \\
\hline 5.3 Recommendation & Yaboo & Yaada & Yaada furmaataa & Yaada/Yaboo (Galmee jechootaa 2005:606) \\
\hline Reference/Bibliography & Wabii & Kitaabilee wabii & Wabiilee & $\begin{array}{l}\text { Madda/Wabii (Wiirtuu Jildii 6, 1993:190;199; Wiirtuu } \\
\text { Jildii 9,2001:222) }\end{array}$ \\
\hline Appendix & Miiltoo & Dabalee/Miiltoo & Dabalee & Miiltoo (Wiirtuu, 1995:91; Jildii10, 2005:225) \\
\hline
\end{tabular}


Appendix C: Proposed Research Course Related Lexes in Afan Oromo for the English Language Lexes

\begin{tabular}{|c|c|c|c|}
\hline $\begin{array}{l}\text { Some Research Related } \\
\text { Lexis in English }\end{array}$ & \multicolumn{2}{|c|}{$\begin{array}{l}\text { Proposed Lexes have been selected and collected from the Oromia Culture and Tourism Bureau's Publication, ie. The WIIRTUUs' (Magazines, } \\
\text { mentioned in the table } 1.1 \text { of this study) and Galmee Jechootaa-Galmee (Dictionary) as indicated under as sources. }\end{array}$} & \multirow[t]{2}{*}{ Remarks } \\
\hline Table of Contents & & Baafata (Wiirtuu 1995:84; Vol. 2, 1989:122; including AST U \& Ambo University) & \\
\hline Acknowledgements & & Galata (Accepted in practice by all sources as seen on Appendix A) & \\
\hline Abstracts & & Axeerara (WIIRTUU, 1995:85) & \\
\hline CHAPTER O NE: INTRODUCTION & BOQONNAA TOKKO: & SEENSA (WIIRTUU, 1995:82) & \\
\hline 1.1 Background & & Ka'insa ykn Ka'iinsa (Galmee 2005:388) & \\
\hline 1.2 Statement of the problem & & Himrakkoo/Ka'umsa (Galmee 2005:383) & \\
\hline 1.3 Objective & & Kaay yoo (Galmee 2005:386) & \\
\hline 1.4 Significance of the study & & Faayidaa (WIIRTUU, Vol. 2, 1989:123) & \\
\hline 1.5 Scope of the study & & Daangaa (Galmee 2005:149) & \\
\hline 1.6 O rganization of the study & & Ijaarama (Galmee jechootaa 2005:348) & \\
\hline CHAPTER TW O : LITERATURE REVIEW & BOQONNAA LAMA: & SAKATTA'A BARRUU & \\
\hline CHAPTER THREE: METHO DS & BOQONNAA SADII: & MALLEEN & \\
\hline 3.1 Data source & & Madda (WIIRT UU, Vol. 6, 1993:190; & \\
\hline 3.2 Sample & & Iddat too ( WIIRTUU, Vol. 10, 2005:220) & \\
\hline 3.3 Tools & & $\begin{array}{l}\text { Meeshaalee (Not found in the three } \\
\text { Universities documents) }\end{array}$ & \\
\hline 3.4 Data analysis & & Xiinxaluu (Wiirtuu, Vol. 11, 2006:222) & \\
\hline $\begin{array}{l}\text { CHAPTER FOUR: DATA PRESENTA TON, } \\
\text { ANALYSIS AND INTERPRETATION }\end{array}$ & BOQONNAA AFUR: & DHIYEESSUU, XIINXALAAFI IBSAA RAGAA & \\
\hline 4.1 Data presentation & & Dhiyeessa raga (Galmee jechootaa 2005:520, 622) & \\
\hline 4.2 Data analysis \& interpretation & & Xiinxala ragaafi ibsa (Wiirtuu Vol. 11, 2006:222) & \\
\hline CHAPTER FIVE: CONCLUSION & BOQONNAA SHAN: & XUMURA (WIIRTUU, 1995:82) & \\
\hline 5.1 Summary & & Cuunfaa & \\
\hline 5.2 Finding & & Argannoo (Galmee jechootaa 2005:41) & \\
\hline 5.3 Recommendation & & Yaboo (Galmee jechootaa 2005:606) & \\
\hline Reference/Bibliography & & Madda/Wabii (WIIRTUUs, Vol. 6, 1993:190,199; \& Vol. 9, 2001:222) & \\
\hline Appendix & & Miiltoo (Wiirtuus 1995:91; and Vol.10,2005:225) & \\
\hline
\end{tabular}




\section{REFERENCES}

[1] Abdallaa Shaafii et. al. (1996). Barnoota Afaan Oromoo, Siilabasii, kutaa 9ffaafi 10ffaa. Finfinne: Biiroo Barnoota Oromiyaa.

[2] Adama Science \& Technonolgy University (June 2012). OROMO RESEARCH CENTRE. SCHOOL OF HUMANITIES and LAW. DEPARTMENT OF AFAN OROMO and LITERATURE.

[3] Addunyaa Brkeessaa (2011). AKKAMTAA: Yaadrimee Qorannoo Hujoo. Finfinnee.

[4] Amio, Rey Carlo L. (NY). The Intellectualization of Filipino through English: Spanish as an Intermediary Language (PDF)

[5] Andrean, Linda (ny :32). A Brief History of the German Lan guage. The Lan guage of Austria, Germany, and Parts of Switzerland

[6] Ashannaafii Tarrafaa fi Masfin Oliiqaa (2012). MALA QU'ANNOO (RESEARCH METHODS). SAGANTAA BARNOOTA FAGOO YUUNIVARSIITII TEEKNOOLOJII ADAAMAA, MUUMME AFAAN OROMOOFI OGUMAA.

[7] COUNCIL OF THE EUROPEAN UNION (21 November 2008). Council Resolution on a European strategy for multilingualism. Brussels.

[8] Council of Europe (2008). Language Education Policy Profile. Austria: Ministry of Education, the Arts and Culture and Ministry of Science and Research Language Policy Division.

[9] Dastaa Dassaalany (2013). Bu'uura Qorannoo. Maxx 2ffaa. Addis Ababa Yunivarsiitii. Far East Treding PLC.

[10] Gumii Qormaata Afaan Oromoo (1997/1995). Wiirtuu-Barruulee Qormaata Waaltina Afaan Oromoo. Finfinnee: Biiroo Aadaafi Ispoortii Oromiyaa. Artistic Printers.

[11] Gumii Qormaata Afaan Oromoo (1989/1997). Wiirtuu-Barruulee Qormaata Waaltina Afaan Oromoo, Jildii 2. Finfinnee: Biiroo Aadaafi Beeksisa Oromiyaa. Commercial Printing Enterprise.

[12] Gumii Qormaata Afaan Oromoo (1990/1998). Wiirtuu: Barruulee Qormaata Waaltina Afaan Oromoo. Jildii 3.Finfinnee: Biroo Aadaafi Beeksisa Oromiyaa. Commercial Printing Enterprise.

[13] Gumii Qormaata Afaan Oromoo (1991/1999). Wiirtuu: Barruulee Qormaata Waaltina Afaan Oromoo, Jildir 4.Finfinne: Biiroo Aadaafi Beeksisa Oromiyaa. Artistic Printing Enterprise.

[14] Gumii Qormaata Afaan Oromoo (1992/200). Wiirtuu: Barruulee Qormaata Waaltina Afaan Oromoo, Jildii 5. Finfinne: Biiroo Aadaafi Beeksisa Oromiyaa. Commercial Printing Enterprise.

[15] Gumii Qormaata Afaan Oromoo (1993/2001). Wiirtuu: Barruulee Qormaata Waaltina Afaan Oromoo, Jildii 6.
Biiroo Aadaafi Beeksisa Oromiyaa. Finfinee: Commercial Printing Enterprise.

[16] Gumii Qormaata Afaan Oromoo (1995/2003). Wiirtuu: barruulee Qormaata Waaltina Afaan Oromoo, Jildii 7. Finfinne: Biiroo Aadaafi Turizimii Oromiy aa. Commercial Printing Enterprise.

[17] Gumii Qormaata Afaan Oromoo (1999). Wiirtuu: barruulee Qormaata Waaltina Afaan Oromoo, Jildii 8. Finfinne: Biiroo Aadaafi Turizimii Oromiyaa. Commercial Printing Enterprise.

[18] Gumii Qormaata Afaan Oromoo (2001). Wiirtuu: barruulee Qormaata Waaltina Afaan Oromoo, Jildii 9. Finfinne: Biiroo Aadaafi Turizimii Oromiyaa. Commercial Printing Enterprise.

[19] Gumii Qormaata Afaan Oromoo (2005). Wiirtuu: barruulee Qormaata Waaltina Afaan Oromoo, Jildii 10. Finfinne: Biiroo Aadaafi Turizimii Oromiyaa. Commercial Printing Enterprise.

[20] Gumii Qormaata Afaan Oromoo (2006). Wiirtuu: barruulee Qormaata Waaltina Afaan Oromoo, Jildii 11. Finfinne: Biiroo Aadaafi Turizimii Oromiyaa. Commercial Printing Enterprise.

[21] ICT Development Office \& Ethiopian Languages and Research Centre of Addis Ababa University (October 2005). ICT Terms in Afaan Oromo. Addis Ababa, Ethiopia ICT Development Agency.

[22] MEKURIA BULCHA (1995). Onesimos Nasib's Pioneering Contributions to Oromo Writing. Sweden: University of Uppsal. Nordic Journal of African Studies 4(1): 36-59

[23] Rosalie Finlayson \& Mbulungeni Madiba (2002). The Intellectualization of the Indigenous Languages of South Africa: Challenges and Prospects, Current Issues in Language Planning, 3:1, 40-61, DOI: $10.1080 / 14664200208668036$

[24] Sileshi Berhanu (2013). OPPORTUNITIES AND CHALLENGES IN TEACHING AND LEARNING AFAN OROMO AS A SECOND LANGUAGE: OROMIA IN FOCUS. PhD Dissertation. ASTU. School of Postgraduate Studies. Afan Oromo and Literature Department.

[25] The Constitution of the Federal Democratic Republic of Ethiopia. (21st August, 1995). Addis Ababa: (n. p.).

[26] The Transitional Government of Ethiopia, Ministry of Education (1994). Education and Training Policy. Addis Ababa.

[27] Wolff, Ekkehard-Prof. Dr. (2012). Public Lecture at Adama Science and Technology University.

i Presented By The Researcher On The $1^{\text {st }}$ National Research Conference (June 24 - 25, 2016) Organized By Arsi University-Ethiopia, Asella 